\title{
Der Verfassungsschutz als Politbüro
}

Der deutsche Rechtsradikalismus weiß nicht wohin. Woher (vor allem im Osten) Glatzköpfe, Springerstiefler, Runenträger und Schlägertrupps kommen, ist dagegen kein Rätsel. Sie haben keine Ausbildungsplätze und keine Arbeit, sind auf die Qualifikationsanforderungen des entwickelten Kapitalismus schlecht vorbereitet, versinken im (auch mit Stütze zugänglichen) TV-Müll und Massenkonsumramsch, stammen zu einem großen Teil aus politisch und sozial derangierten Familien und haben mit den Wahlkämpfen um Steuersenkungen und Atomkonsens schlechterdings nichts zu tun. Zwischen Porno, Baseballschläger und Bierdosen wird so ein Nationalismusanfall geradezu zum Sublimierungsakt. Mit der kriminellen Seite, dem Abfackeln von Ausländerheimen und Spontantotschlagsaktionen, scheint der hochgerüstete Sicherheitsstaat nach und nach fertig zu werden, auch wenn zunächst einige müde Richter gegenüber unreifen Tätern Milde und Bewährung wegen schlechter Kindheit obwalten ließen. Die Ortsbezeichnungen, die für Ausländerhaß standen, verblassen langsam in der Erinnerung. Stattdessen wird das Desinteresse im Westen durch Aufmärsche gestört, wenn Demos mit prallen Jungmännern abrollen. Diese tragen zwar keine Waffen, wenn man von ihren hart beschuhten Füßen absieht, haben aber einen martialischen SA-Touch. Wären nicht Gegendemos mit wesentlich mehr jungen Leuten auf der Straße und verhinderten die Ordnungskräfte nicht mit massivem Personaleinsatz eine Konfrontation, wäre auch im Westen Alarm geboten. Demgegenüber kann im Osten die Alltagspräsenz der Rechtsradikalen auf vielen öffentlichen Plätzen nicht nur schwarzafrikanischen Studenten Angst machen.

Für mehr als subkulturellen Individualterror und sektenartige Demoauftritte bedürften die Rechtsradikalen allerdings über halbe NS-Symbole und fremdenfeindliche Parolen hinaus eines gewissen Maßes an Programm und Theorie, wie sie auch durch einen Parteistatus vorgegeben sind. Die NPD, als gefährlichste Gruppierung der Rechtsradikalen in das Verbotsverfahren vor dem Bundesverfassungsgericht gezogen, bietet dem Jungvolk zwar allerlei Ertüchtigungsprogramme und Schlagworte, leidet aber offenbar unter gedanklicher Anämie. Es fehlt sogar ein bräuhaus-fähiger Parteichef wie Schönhuber, der immerhin viele Jahre Rundfunksendungen für bayerische Hörer produziert hatte, bevor er F.J. Strauß rechtsradikal zu überholen begann. Hetzreden, wie sie Le Pen früher zu halten pflegte, in denen Frankoalgeriern höchstens die Stufe niedriger Lebewesen zugebilligt wurde, weit unterhalb des von seiner Freundin Brigitte Bardot geschützten Tierniveaus, könnten zwar Theoriemangel am ehesten überdecken, würden aber wegen der internationalen Furcht vor einem deutschen Postnationalsozialismus auf schnelle Kriminalisierung wegen Volksverhetzung etc. stoßen. Mit der Lektüre von »Mein Kampf « ist bislang auch nichts zu gewinnen. In Deutschland darf dieses Pamphlet noch nicht einmal gedruckt werden und wer von den latenten Nationalsozialisten liest es schon gern auf englisch, selbst wenn die Internet-Provider seine Zugänglichkeit verbürgen? Vielleicht hat ja Walter Seitz Erfolg, dieser literarisch ambitionierte Münchner Richter, der in der Neuen Juristischen Wochenschrift das Publikationsverbot für Adolf Hitlers Hauptwerk mit korrektem Abscheu aufzuheben gefordert hat (NJW 2002, 572), damit wir uns mit diesem offen und frei auseinandersetzen können. Der Führer, ursprünglich ja ein bloßes Medium (Karl Kraus) aller reaktionären Absteiger, Untertanengeister und Militärfetischisten, verbog Antikapitalismus in Antisemitismus und setzte Versailles, der Niederlage, den Herrenmenschen entgegen. So krude sich das aus der Festung 
Landsberg ergoß, so facettenreich war das Spektrum der deutschnationalen Auffangpositionen der Rechten in den $20 e r$ und 3 oer Jahren, das von Carl Schmitt bis zu Martin Heidegger und Gottfried Benn reichte.

Nichts davon ist heute recht anschlußfähig. Die junge Rechte, die gelegentlich in der FAZ schreibt, weiß zu genau, daß die Wirtschaft nichts Nationales braucht. Botho Strauß und Sloterdijk schrecken tief gekränkt zurück, wenn ihnen mehr Elitismus und Züchtungsphantasie attestiert wird, als ihre Bocks- und Schaumgesänge hergeben. Schills Innovationskraft beschränkt sich offenbar auf Polizistenanwerbung gegen Drogenhändler in Bahnhofsnähe. In den Landesparlamenten saßen und sitzen für NPD und DVU nur Kleinbürger und Hausfrauen, die kaum die ihnen vom Verband oder vom Verleger Frey aus München zugesteckten Texte bruchlos ablesen können. Bei solchem Elend wird die Suche nach Ghostwritern prekär. Dem rechtsradikalen Ressentiment ein parteiverbotsfähiges Programm zu geben, wird so automatisch zur staatlichen Aufgabe. »Übernehmen Sie, meine Herren! Das Bundesamt für Verfassungsschutz hat sich dieser Herausforderung nicht versagt, lang vor Schilys Zeiten. Ein Übermaß an Vorbereitung brauchten die Unterwanderer nicht, um in Programmkommissionen und auf Rednertribünen zu gelangen.

Wie war das noch vor Zeiten anders, als das Bundesamt sich in den 7oer Jahren mit den Strömungen der Alten und Neuen Linken auseinandersetzen mußte. Es war eigentlich nur darauf vorbereitet, die Kfz-Kennzeichen rund um DKP-Veranstaltungen zu notieren, und nicht darauf, ideologische Vorgaben zu machen oder auch nur die Anhörungen der Berufsverbotskandidaten zu steuern. Referendariatsbewerber, Junglehrer und Postbeamtenanwärter hatten Hegel, Marx, Engels, Proudhon, Bakunin, Lenin, Trotzki, Mao, Horkheimer, Adorno und Marcuse im Tornister und erwiesen sich bei den Anhörungsverfahren allzu oft als intellektuell so überlegen, daß dringend Hilfe vom Verfassungsschutz erbeten wurde. In der Not fertigte SPD-Mann Frisch, nachher verdientermaßen Präsident des Bundesverfassungsschutzes geworden, eine Art Anhörungsfibel mit dem Tiefgang einer Führerscheinbroschüre, in der er den junge Revoluzzern immer wieder die Diktatur des Proletariats, den Gulag und Stalin, Stalin, Stalin entgegenzuhalten empfahl. Argumentative Flexibilität, etwa dahin, daß die Diktatur des Proletariats eine archaische Metapher für eine demokratische Mehrheitsherrschaft sein sollte, nützten den Angehörten ebensowenig wie die Versicherung, daß Stalin und sein Gulag asiatische Verirrungen gewesen seien. Die meisten Staatsamtsbewerber verließen aber ungeachtet des geringen Niveaus der Checkliste des Verfassungsschutzes ihre Anhörungen in dem sicheren Gefühl, die Anhörer ins Nachdenken gebracht zu haben, was dann jedoch nicht durch Einstellungsbescheide verifiziert wurde. Auch wenn sich die Wiederbelebung der Theorien des I9. Jahrhunderts nicht als tragfähig erwiesen hat, provozierte die intellektuelle Defensive, in die der Verfassungsschutz bis in die 8oer Jahre gedrängt wurde, geradezu ein Übermaß an Abwehrhaltung, so daß kein kommunistischer Postbote mit den Drucksachen des Handels und der Industrie die Briefkästen der Villenviertel bedienen durfte.

Nach der Auflösung der Sowjetunion und der Wiedervereinigung Deutschlands suchte der Verfassungsschutz dann händeringend neue Aufgaben. Die Infiltration der Rechten bot sich schon deswegen an, weil die dafür zuständige Volkspartei den rechten Rand jeweils möglichst integrieren will. Ohne eine über $4 \%$ der Wählerstimmen verfügende NPD hätte schon Willy Brandt 1969 nicht gewonnen. Die geistigen Hürden für die Undercoverarbeit waren denkbar gering. Mancher rechte Verfassungsschutzbeamte konnte von seinen zwei Seelen eine ohne jede Verwandlung in die NPD implantieren. Und wer auch nur einigermaßen schlüssig formulieren konnte, mußte über kurz oder lang aufrücken, auch in die Parteispitze. Wie sympathisch muß die Bescheidenheit gewirkt haben, mit der sich Verfassungsschützer 
beim Angebot einer Führungsposition Bedenkzeit (bis zur Billigung durch das Bundesamt) erbeten haben. So kam, was heute keiner so gewollt haben will: wo die NPD-Hasen ankamen, waren die Verfassungsschutzigel schon da.

Was aber sollte der Verfasssungsschutz der NPD ins Programm schreiben? Wo Hitler schon legal zur Macht gestrebt hatte, war - in schwierigerer Zeit - Legalität des Parteihandelns unabweisbares Gebot. Straftaten sollten nur Individuen zugeschrieben werden können. Vom Traditionsgut des Nationalismus blieb wenig: zu postulieren war allenfalls eine gewisse Überlegenheit der germanischen oder deutschen Rasse, auch wenn Herrenmenschentum im Hinblick auf die Ausbreitung des Konsumschlaffitypus irreal erscheint. Auch »Deutschland den Deutschen« ist eine zweischneidige Parole, wo doch auch die potentiellen NPD-Wähler lieber auf Mallorca, Teneriffa oder in Italien leben würden, ganz abgesehen vom Stolz über den Mercedesabsatz in den USA und China. Ausländerhaß wäre noch die beste Grundlage für ein Parteiprogramm rechts von Roland Koch, auch wenn ihm die verdeckten Verfassungsschützer die traditionelle Pointe, den Antisemitismus, abbrechen müssen. Die Verwicklung in Antisemitismus könnte, wenn das in New York, Washington und Tel Aviv falsch verstanden würde, zur Massenentlassung aus den Beförderungsrängen des Bundesamtes führen. So bleibt die Vertreibung der Einwanderer aus Ost und Süd der machbare Kern einer NPD-Programmatik aus Verfassungsschutzfeder, verbunden mit ein bißchen NS-Folklore.

Es ist eine schwierige Gratwanderung. Die rot-grüne Regierung macht ein Zuwanderungsgesetz, weil sie weiß, daß sie schon bevölkerungspolitisch mehr qualifizierte Junge braucht, die zur härtester Arbeit bereit sind. Nur so kann der Sozialstaat gehalten werden. Hinzukommen müßte ein umfassendes Programm für die Qualifikation der jungen Arbeitslosen, das freilich schwerer zu realisieren wäre als Spaziergänge des Kanzlers in Fußgängerzonen, denn die Wirtschaft erhofft sich eine bessere Auswahl unter den Zuwanderern als unter den Dauerarbeitslosen im Osten. Das Bundesamt für Verfassungsschutz aber entwirft die Abwanderungsprogrammatik. Als Politbüro der NPD soll es der bundesdeutschen Gesellschaft die Erreger des Rechtsradikalismus, insbesondere des Fremdenhasses infizieren. Vielleicht bricht die Krankheit aus, vielleicht tritt aber auch ein Impfeffekt ein. Ein aleatorischer Selbstversuch, der paradoxerweise auch noch in puncto NPD verboten werden soll, bei den anderen Rechtsparteien aber weitergehen kann. Das Verfahren vor dem Bundesverfassungsgericht mutiert so zu einer Art In-Sich-Prozeß, bei dem der Staat sowohl für das Programm wie für dessen Verbot zuständig ist. Das Bundesverfassungsgericht reagiert gekränkt, als es den Zusammenhang erfährt. Eine gekränkte Institution? Ist die Ehre uneingeweihter Verfassungshüter verletzt? Es weiß doch keiner, was bereits üblich und was erlaubt ist. Die Kränkung ist also nichts anderes als ein analytisches Defizit. 